\title{
New insights in respiratory impedance in young children after repair of congenital diaphragmatic hernia: a cross-sectional study
}

\author{
Giuliana Ferrante ${ }^{1 * \dagger}$, Giovanna Cilluffo ${ }^{2 \dagger}$, Maria Rita Di Pace ${ }^{1}$, Giovanni Corsello ${ }^{1}$, Enrico Lombardi ${ }^{3}$, \\ Raffaele L. Dellacà ${ }^{4}$, Velia Malizia² and Stefania La Grutta²
}

\begin{abstract}
Lung function impairment is common in Congenital Diaphragmatic Hernia (CDH) survivors. The aim of this study was to evaluate, in children who underwent CDH surgical repair, mid and long-term consequences on respiratory impedance, investigating the impact of $\mathrm{CDH}$ on both resistance and reactance parameters, as well as bronchodilator response.

Forced Oscillation Technique (FOT) parameters were collected from 12 patients ( $2-11$ years). Resistance and reactance values at $8 \mathrm{~Hz}\left(\operatorname{Rrs} 8, X_{r s} 8\right)$ and the area under the reactance curve (AX) were measured pre and post-salbutamol. Quantitative variables were compared using Mann-Whitney $U$ test. Differences of categorical variables were evaluated using Fisher exact test. Statistically significant differences between measured and predicted values for Rrs8 ( $p=0.04)$, Xrs8 $(p=0.02)$ and AX ( $p=0.01)$ were found. When stratifying for age, significant difference between measured and predicted values was observed only in children $<5$ years $(n=6)$ (Rrs8 $p=0.03, \operatorname{Xrs} 8 p=0.001, \operatorname{AX} p=0.007)$. With respect to children 5 years $(n=6)$, the younger ones showed higher $z$-scores in Rrs $(p=0.015)$, Xrs $8(p=0.002)$ and AX $(p=0.002)$ values. Since the $z$-score difference was greater than 0.5 , it was considered a difference clinically relevant. No differences in bronchodilator response were recorded.

In children with $\mathrm{CDH}$ an impairment of respiratory impedance measured by FOT is observed only in children aged less than 5 years.
\end{abstract}

Keywords: Children, Congenital diaphragmatic hernia, Forced oscillation technique, Lung function, Respiratory impedance

To the Editor,

Congenital diaphragmatic hernia $(\mathrm{CDH})$ is a rare malformation of the lung, occurring in 1-5/10,000 births (https://www.orpha.net), due to a defect in the diaphragm that allows abdominal organs to move into the chest cavity. Variable degrees of impairment of lung function in $\mathrm{CDH}$ survivors have been reported throughout childhood [1], though compensatory lung

\footnotetext{
* Correspondence: giuliana.ferrante@unipa.it

Giuliana Ferrante and Giovanna Cilluffo are primary authors.

${ }^{1}$ Department of Health Promotion Sciences Maternal and Infant Care, Internal Medicine and Medical Specialities, University of Palermo, via del Vespro 129, 90127 Palermo, Italy

Full list of author information is available at the end of the article
}

growth is expected to be completed by the age of 6 years [2].

The Forced Oscillation Technique (FOT) provides detailed characterization of the resistance (Rrs) and reactance (Xrs) of the respiratory system over a wide range of frequencies, which respectively reflect the frictional losses and the energy storage (elastic and inertial) properties of the respiratory system. Moreover, FOT is able to detect reversible airway obstruction in children. The resistance measured contains contributions from both the lung and chest wall, whereas reactance yields information about the elastic properties of the lung. In general, lower frequency data reflect the peripheral regions of the lung, while higher frequency data are most

(c) The Author(s). 2019 Open Access This article is distributed under the terms of the Creative Commons Attribution 4.0 International License (http://creativecommons.org/licenses/by/4.0/), which permits unrestricted use, distribution, and 
representative of the central airways [3]. To our knowledge, only one study evaluated lung function by means of FOT in children surviving after $\mathrm{CDH}$ repair, finding that resistance at $8 \mathrm{~Hz}(\mathrm{Rrs} 8)$ was increased in $60 \%$ of the patients [4]. However, this study did not explore changes to respiratory reactance, which provides much more sensitive information on lung periphery compared to Rrs8, nor the bronchodilator response.

The aim of this study was to evaluate, in children who underwent $\mathrm{CDH}$ surgical repair, mid and long-term consequences on respiratory impedance, investigating the impact of $\mathrm{CDH}$ on both resistance and reactance parameters, as well as bronchodilator response.

From 2003 to 2011, a total of 16 children born with $\mathrm{CDH}$ referred to the Pediatric Surgical Unit of the University of Palermo, Italy, underwent surgical repair at birth. As a part of their multidisciplinary follow-up, $\mathrm{CDH}$ children aged 2-11 years were enrolled at the Pediatric Pulmonology Outpatient Clinic of the IBIM National Research Council (CNR) in Palermo, Italy. Twelve (75\%) agreed to participate in the study. Mental retardation $(n=1)$, emigration $(n=1)$ and absence of follow-up $(n=2)$ were causes of exclusion from the study. Clinical characteristics were comparable between participants and those not included (Table 1).

The study was performed in accordance with the Declaration of Helsinki and Good Clinical Practice guidelines; it was approved by the local ethics committee and registered on the central registration system (NCT02466451).

Inclusion criteria were the following: (i) history of $\mathrm{CDH}$; (ii) surgical repair at birth; (iii) written informed consent; (iv) ability to undergo FOT. Exclusion criteria were the following: (i) major congenital cardiac, pulmonary and neurological anomalies [5]; (ii) immunological and/or metabolic disease; (iii) upper or lower respiratory tract infections in the last 2 weeks; (iv) therapies with antibiotics and/or corticosteroids in the last 2 weeks.

Detailed medical information on prenatal $\mathrm{CDH}$ ultrasound diagnosis, mode of delivery, Apgar score, birth weight, duration of artificial ventilation and hospitalization, surfactant administration, CDH defect size, surgical repair, personal history of respiratory infections and gastroesophageal symptoms, current passive smoking exposure, was obtained by trained medical investigators.

Height and weight were measured using a stadiometer (Wunder HR1, Italy) and an electronic weighing scale (Seca, Hamburg, Germany). Respiratory impedance was measured using the Quark i2 $\mathrm{m}^{\bullet}$ Forced Oscillation Measurement system (Cosmed, Italy) based on a pseudo-random noise signal between 4 and $48 \mathrm{~Hz}$, according to the ATS/ERS recommendations [6]. Subjects were seated with the head in a neutral position, wearing a nose clip and breathing into a mouthpiece connected to the device; the cheeks and the floor of the mouth were gently supported by one of the investigators. Only measurements with a minimal coherence function of $95 \%$ and a coefficient of variation $<15 \%$ were considered valid. The mean value of three valid measurements was retained [3]. Bronchodilator response (BD) was evaluated repeating measurements $15 \mathrm{~min}$ after inhalation of salbutamol $200 \mu \mathrm{g}$ [3] administered via a metered dose inhaler through a plastic spacer device (Aerochamber Plus ${ }^{\circ}$, Trudell Medical International, Canada).

Table 1 Comparison of clinical characteristics of included and excluded participants

\begin{tabular}{|c|c|c|c|}
\hline & Included & Excluded & $p$-value* \\
\hline & $n=12$ & $n=4$ & \\
\hline Inborn delivery & $3(27 \%)$ & $4(100 \%)$ & 0.056 \\
\hline 1-min Apgar score & $6(4.5-6.5)$ & $5(5.0-5.5)$ & 0.749 \\
\hline 5-min Apgar score & $8(8.0-9.25)$ & $9(8.5-9.0)$ & 0.540 \\
\hline Duration of artificial ventilation, days & $6(6-13)$ & $25(16.0-31.25)$ & 0.160 \\
\hline Total hospitalization length, days & $24(17.75-35.25)$ & $60(60-60)$ & 0.098 \\
\hline Surfactant administration & $3(30 \%)$ & $1(25 \%)$ & 1.000 \\
\hline Type of defect size ${ }^{a}$ & & & 0.784 \\
\hline B & $6(50 \%)$ & $3(75 \%)$ & \\
\hline C & $5(41 \%)$ & $2(25 \%)$ & \\
\hline D & $1(8 \%)$ & $0(0 \%)$ & \\
\hline Surgical repair & & & 0.379 \\
\hline Primary closure & $9(75 \%)$ & $2(50 \%)$ & \\
\hline Patch reconstruction & $3(25 \%)$ & $2(50 \%)$ & \\
\hline
\end{tabular}

Data are presented as $\mathrm{n}(\%)$ or median (25th-75th percentiles). *Fisher information test or Mann-Whitney U test; ${ }^{2}$ Congenital Diaphragmatic Hernia Study Group. Congenital diaphragmatic hernia: defect size correlates with developmental defect. J Pediatr Surg. 2013;48:1177e82 
Considering a sample size of 12 subjects, a power of about $79 \%$ in detecting a standardized effect size of 0.8 through a proportion test with a 5\% family-wise error rate was obtained. Quantitative variables were compared using the Mann-Whitney U test. Differences of categorical variables were evaluated using the Fisher exact test. Z-scores of Rrs8, Xrs8 and the area under the reactance curve (AX) were computed according to equations established by Calogero et al. [3]. Analyses were performed using R (3.4.1) statistical software; a $p$-value $<0.05$ was considered significant and a difference of 0.5 in Z-scores was considered clinical relevant [7] .

$\mathrm{CDH}$ was diagnosed prenatally by ultrasound in four patients with type "C" and in one with type " $D$ " defect size [8]; no mentions of observed/expected lung volumes measurements were available. All children (41.67\% males, mean age $5.01 \pm 2.69$ years) were full-term born (mean gestational age $39.7 \pm 0.96$ weeks) by cesarean section. Mean birth weight was $2847.5 \pm 571.84 \mathrm{~g}$, and $17 \%$ were small for gestational age. At the time of the examination, $25 \%$ suffered from lower respiratory tract infections in the first 2 years of life and 33\% had doctor diagnosed gastroesophageal reflux, and $42 \%$ were currently exposed to passive smoking.

All children successfully underwent FOT measurement. The difference in Rrs8 (Fig. 1, panel A), Xrs8 (panel B) and AX (panel C) absolute values from their predicted ones in relation to age were greatest in younger children and reduced with age for the older patients. Differences between measured and predicted values were significant for Rrs8 $(p=0.04)$, Xrs8 $(p=0.02)$ and AX $(p=0.01)$.

In Table 2, comparisons between $\mathrm{CDH}$ children aged $<5$ years and $\geq 5$ years are reported. No significant differences between study groups were found in clinical characteristics. Younger children had significant higher $\mathrm{z}$-scores and higher \%predicted FOT parameters.

Figure 2 depicts pre and post-BD Rrs 8 (panel A), Xrs 8 (panel $\mathrm{B}$ ), and $\mathrm{AX}$ (panel $\mathrm{C}$ ) values in relation to age: differences between pre and post-BD values decreased when age increased.

This study reports the mid- and long-term consequences on respiratory impedance in a sample of children with non severe $\mathrm{CDH}$ after surgical repair. Significant differences between measured and predicted values for Rrs8, Xrs8 and AX were found, confirming that an impairment of respiratory resistance and reactance is detectable throughout childhood in $\mathrm{CDH}$ survivors. Moreover, according to previous studies, these data are suggestive of gradual normalization of lung function in $\mathrm{CDH}$ children over time [2,9]. In this connection, we found that respiratory function was only impaired in children aged less than 5 years, whereas near normal respiratory impedance was observed in older children, probably thanks to compensatory lung growth. Abnormalities both in the resistive and in the reactance components of respiratory impedance might be due to the different degree of damage induced by prenatal $\mathrm{CDH}$, resulting in a reduction in total number of alveoli and in hypoplastic lungs. Indeed, the observed significantly higher than predicted Rrs8 values account for an increased total resistance of the respiratory system. Furthermore, children with $\mathrm{CDH}$ showed an increased Xrs8 compared to predicted values, which probably has to be ascribed to heterogeneous development of the bronchial tree as well as peripheral obstruction and decreased lung compliance [10]. The finding of increased differences of all the measured FOT parameters compared to their predicted ones only in younger children suggests that lung hypoplasia could play the major role in impairment of lung function in children with non-severe $\mathrm{CDH}$, at least until school age. Indeed, pathological examination demonstrated different degrees of lung hypoplasia with too few or to small alveoli and/or normal or diminished number of conducting airways, in $\mathrm{CDH}$ patients and in animal models [11]. Moreover, the abnormal lung tissue development could result in the formation of large-size alveoli or emphysema [12]. Data from animal models
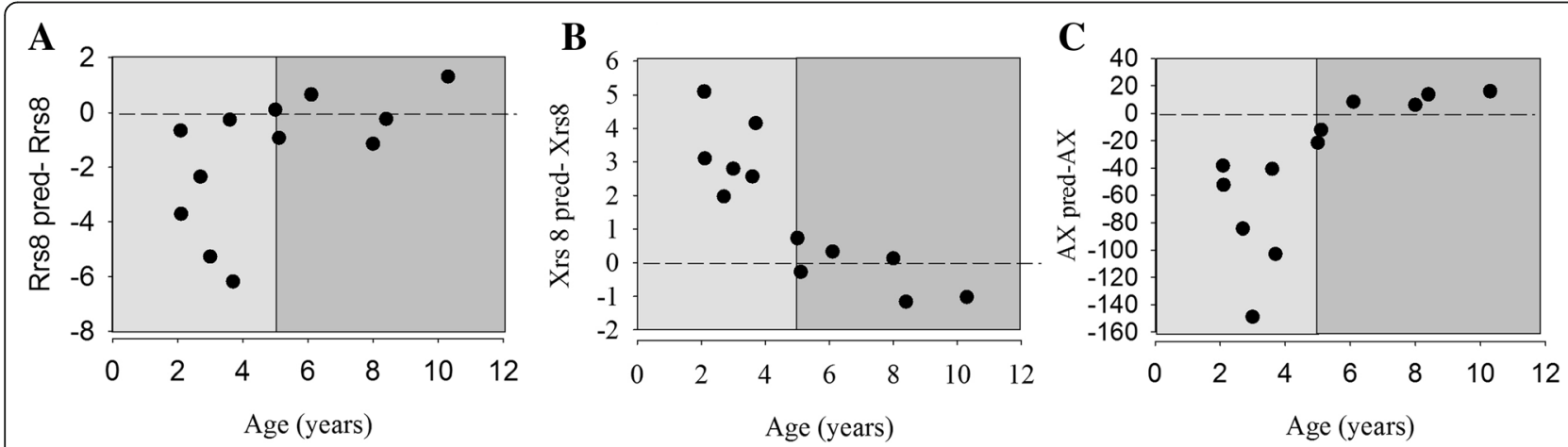

Fig. 1 Distribution of differences from predicted values of Rrs8 (panel a), Xrs8 (panel b), AX (panel c). Points in light grey and in dark grey sides of the figure indicate differences from predicted values of Rrs8, Xrs8, AX in children aged $<5$ years and in children aged $\geq 5$ years, respectively 
Table 2 Patients characteristics, initial management and respiratory impedance by age

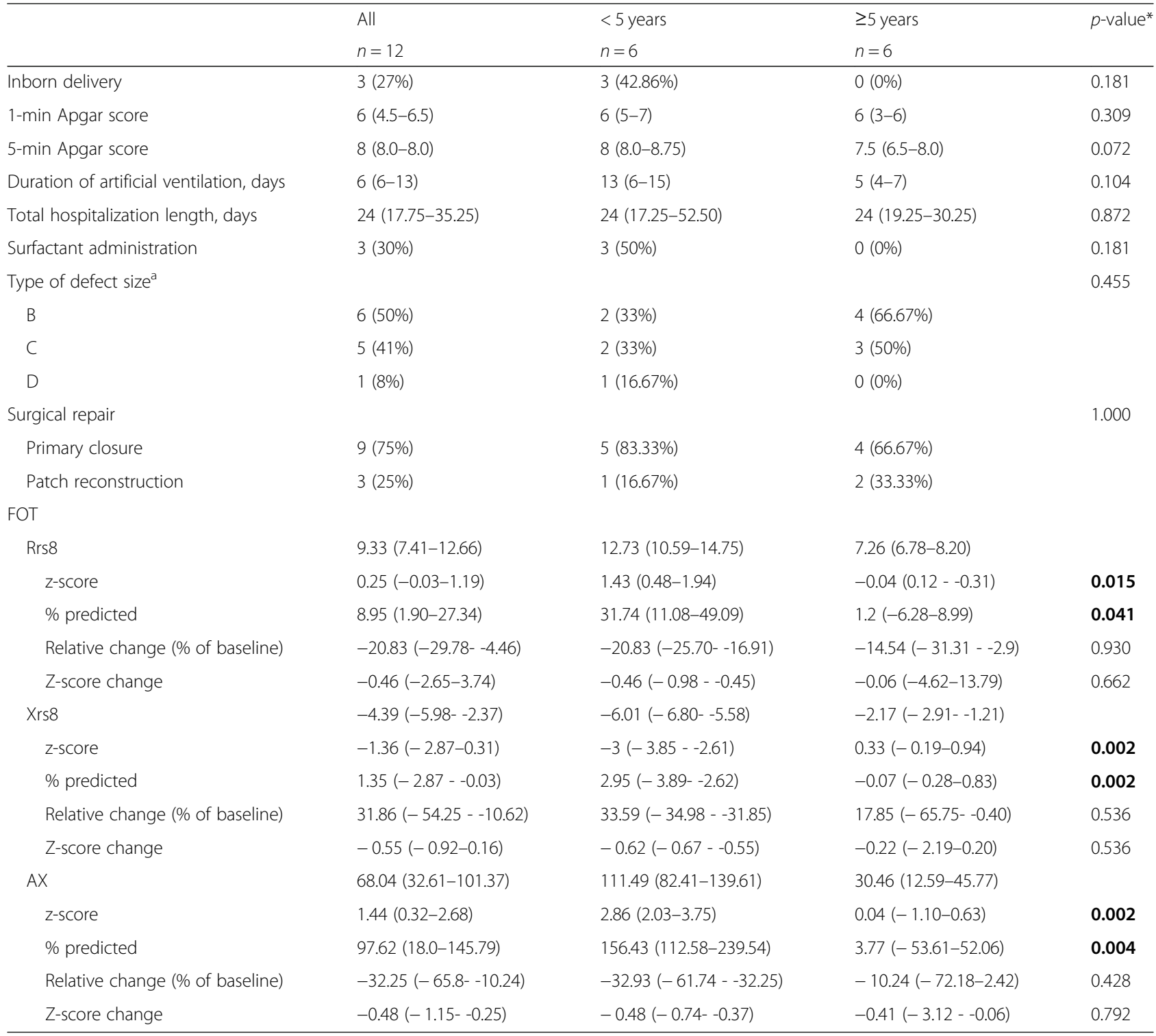

Data are presented as $\mathrm{n}$ (\%) or median (25th-75th percentiles). *Fisher information test or Mann-Whitney U test; *one missing value. ${ }^{\mathrm{a} C o n g e n i t a l}$ Diaphragmatic Hernia Study Group. Congenital diaphragmatic hernia: defect size correlates with developmental defect. J Pediatr Surg. 2013;48:1177e82. $p$-values in bold are significant (<0.05)

showed that in $\mathrm{CDH}$ fetuses, low frequency Rrs and Xrs are compromised, suggesting that lung hypoplasia most likely affects mechanical properties of peripheral lung tissue [11]. The lung tissue distortion may contribute to an increase in lung elastic recoil [13]. Thus, the impaired respiratory impedance resulting in more negative values of reactance, suggests that FOT is able to describe the increase in energy expenditure to overcome the elastic components of the lung. Overall, this changes may introduce gas distribution inhomogeneity, which could be properly investigated through the application of a more suitable test, such as the Multiple Breath Washout. Therefore, future studies could be useful to explore this research area and to examine possible correlations with
FOT. With regard to bronchodilator response, we did not observe significant differences between the two age subgroups.

Our study faced certain limitations. Firstly, given the small sample size, the current results need to be confirmed in larger populations. Secondly, the present data cannot be generalized to children with more severe $\mathrm{CDH}$ as half of the children in our sample were affected by type "B" defect (small $-<50 \%$ - portion of the chest wall devoid of diaphragm tissue), $75 \%$ had primary closure and only an average 6-day artificial ventilation with no need of extracorporeal membrane oxygenation. Lastly, the cross-sectional design of the study is another potential weakness; a longitudinal follow-up evaluation 


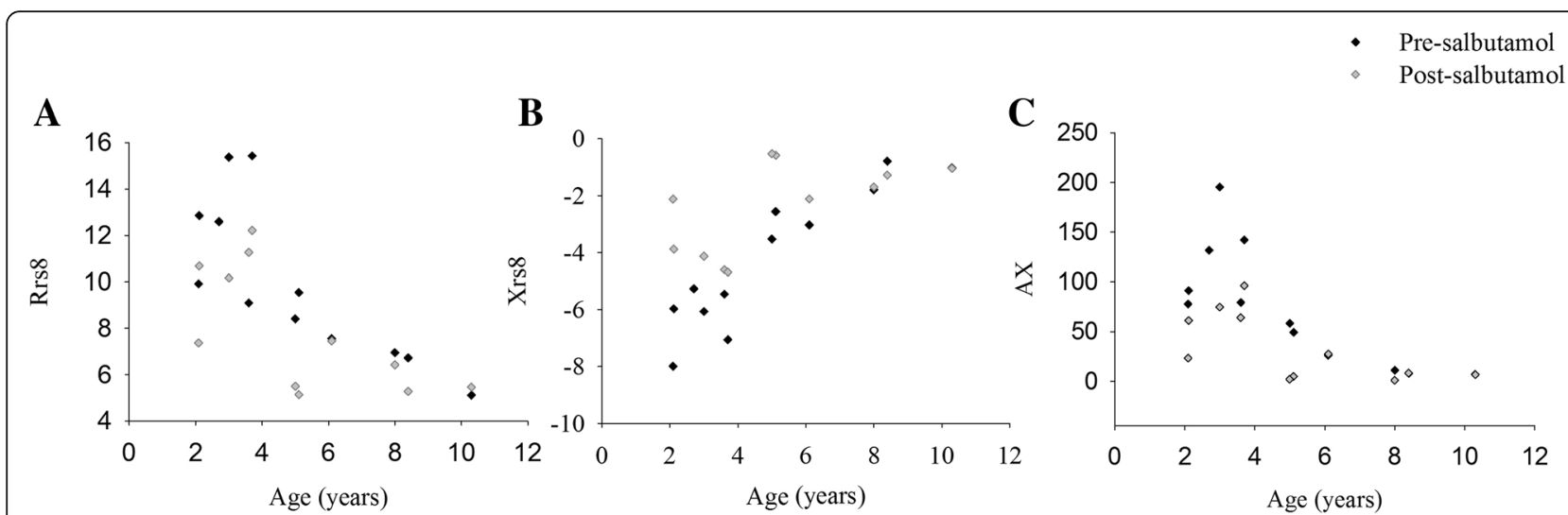

Fig. 2 Distribution of pre and post BD Rrs8 (panel a), Xrs8 (panel b) and AX (panel c) and age. Black and grey squares represent the pre-BD and the post-BD measurements, respectively

would be useful in assessing the sequential changes in pulmonary function.

This is the first study in children with $\mathrm{CDH}$ evaluating both resistance and reactance components of respiratory impedance using FOT. This technique was able to detect alterations in the respiratory function in young children with $\mathrm{CDH}$, shedding some light on a grey zone that cannot be thoroughly assessed by forced expiratory maneuver using spirometry. Indeed, FOT has proved to be more sensitive than forced expiration in investigating subclinical airway abnormalities [14] and is considered a useful tool for evaluating basal airway obstruction and its reversibility in young children $[3,15]$.

In conclusion, in patients with non-severe $\mathrm{CDH}$ who underwent surgical repair, an impairment of respiratory impedance persists until school age; additionally, the higher, although not significant, difference in both the resistance and reactance components after bronchodilator suggests that changes in airway tone can be easily detected by the application of FOT in these children. Despite the small sample size, the present results suggest that a multidisciplinary follow-up including the evaluation of respiratory impedance should be performed in children with non-severe $\mathrm{CDH}$, at least until school age [16].

\section{Abbreviations}

AX: Area under the reactance curve; $\mathrm{CDH}$ : Congenital diaphragmatic hernia; FOT: Forced Oscillation Technique; Rrs: Resistance; Xrs: Reactance

\section{Acknowledgements}

We are grateful to children and parents who made the study possible.

\section{Authors' contributions}

GF and SLG designed the study. MRDP was responsible for the surgical treatment of the enrolled children. VM contributed to the data collection. GC conducted the statistical analyses. GC, GF and SLG wrote the initial draft and had final responsibility for the decision to submit for publication. Giovanni Corsello, EL and RLD performed a critical revision of the manuscript and offered precious technical advice on how the study might be improved. All authors provided substantial contributions to the conception or design of the work, or the acquisition, analysis, or interpretation of data for the paper, revised the manuscript for important intellectual content, approved the final version, and agreed to be accountable for all aspects of the work.

Funding

There is no funding source.

Availability of data and materials

The datasets used and/or analysed during the current study are available from the corresponding author on reasonable request.

\section{Ethics approval and consent to participate}

This study was performed in accordance with the Declaration of Helsinki and Good Clinical Practice guidelines; it was approved by the local ethics committee and registered on the central registration system (NCT02466451): written informed consent was provided by parents of all participants.

\section{Consent for publication}

Not applicable.

\section{Competing interests}

The authors declare that they have no competing interests.

\section{Author details}

'Department of Health Promotion Sciences Maternal and Infant Care, Internal Medicine and Medical Specialities, University of Palermo, via del Vespro 129, 90127 Palermo, Italy. ${ }^{2}$ National Research Council of Italy, Institute of Biomedicine and Molecular Immunology, via Ugo La Malfa 153, 90146 Palermo, Italy. ${ }^{3}$ Pediatric Pulmonary Unit, "Anna Meyer" Pediatric University-Hospital, Viale G. Pieraccini 24, 50139 Florence, Italy. ${ }^{4}$ Dipartimento di Elettronica, Informazione e Bioingegneria, Politecnico di Milano University, Milano, Italy

Received: 21 March 2019 Accepted: 17 June 2019

Published online: 15 July 2019

References

1. Panitch $H B$, Weiner DJ, Feng $R$, et al. Lung function over the first 3 years of life in children with congenital diaphragmatic hernia. Pediatr Pulmonol. 2015;50:896-907.

2. Wohl MEB, Griscom NT, Strieder DJ, et al. The lung following repair of congenital diaphragmatic hernia. J Pediatr. 1977;90:405-14.

3. Calogero C, Simpson SJ, Lombardi E, et al. Respiratory impedance and bronchodilator responsiveness in healthy children aged 2-13 years. Pediatr Pulmonol. 2013:48:707-15.

4. Basek P, Bajrami S, Straub D, et al. The pulmonary outcome of long-term survivors after congenital diaphragmatic hernia repair. Swiss Med Wkly. 2008;138:173-9 
5. Lally KP, Lasky RE, Lally PA, et al. Standardized reporting for congenital diaphragmatic hernia-an international consensus. J Pediatr Surg. 2013;48: 2408-15.

6. Beydon N, Davis SD, Lombardi E, et al. An official American Thoracic Society/European Respiratory Society statement: pulmonary function testing in preschool children. Am J Respir Crit Care Med. 2007;175:1304-45.

7. Hall GL, Thompson BR, Stanojevic S, Abramson MJ, Beasley R, Coates A, Dent A, Eckert B, James A, Filsell S, Musk AW, Nolan G, Dixon B, O'Dea C, Savage J, Stocks J, Swanney MP. The global lung initiative 2012 reference values reflect contemporary Australasian spirometry. Respirology. 2012;17(7): 1150-1.

8. Congenital Diaphragmatic Hernia Study Group. Congenital diaphragmatic hernia: defect size correlates with developmental defect. J Pediatr Surg. 2013;48:1177-82

9. Haliburton B, Mouzaki M, Chiang M, et al. Pulmonary function and nutritional morbidity in children and adolescents with congenital diaphragmatic hernia. J Pediatr Surg. 2017;52:252-6.

10. Marchal F, Loos N. Respiratory oscillation mechanics in infant and preschool children. Eur Respir Mon. 1997;5:58-87.

11. Flemmer AW, Jani JC, Bergmann F, Muensterer OJ, Gallot D, Hajek K, Sugawara J, Till H, Deprest JA. Lung tissue mechanics predict lung hypoplasia in a rabbit model for congenital diaphragmatic hernia. Pediatr Pulmonol. 2007:42(6):505-12.

12. Inselman LS, Mellins RB. Growth and development of the lung. J Pediatr. 1981;98(1):1-15.

13. Bates $\mathrm{JH}$. Systems physiology of the airways in health and obstructive pulmonary disease. Wiley Interdiscip Rev Syst Biol Med. 2016;8(5):423-37.

14. Brochard L, Pelle G, De Palmas J, et al. Density and frequency dependence of resistance in early airway obstruction. Am Rev Respir Dis. 1987;135:579-84.

15. Skylogianni E, Douros K, Anthracopoulos MB, Fouzas S. The forced oscillation technique in paediatric respiratory practice. Paediatr Respir Rev. 2016;18:46-51.

16. Tracy S, Chen C. Multidisciplinary long-term follow-up of congenital diaphragmatic hernia: a growing trend. Semin Fetal Neonatal Med. 2014;19: 385-91.

\section{Publisher's Note}

Springer Nature remains neutral with regard to jurisdictional claims in published maps and institutional affiliations.

Ready to submit your research? Choose BMC and benefit from:

- fast, convenient online submission

- thorough peer review by experienced researchers in your field

- rapid publication on acceptance

- support for research data, including large and complex data types

- gold Open Access which fosters wider collaboration and increased citations

- maximum visibility for your research: over $100 \mathrm{M}$ website views per year

At $\mathrm{BMC}$, research is always in progress.

Learn more biomedcentral.com/submissions 